\title{
Multiple factors associated with life satisfaction in older adults
}

\author{
Shahab Papi ${ }^{1}$, Maria Cheraghi ${ }^{2}$ \\ ${ }^{1}$ Social Determinant of Health Research Center, Ahvaz Jundishapur University of Medical Sciences, Ahvaz, Iran \\ ${ }^{2}$ Department of Public Health, School of Health, Social Determinant of Health Research Center, Ahvaz Jundishapur University \\ of Medical Sciences, Ahvaz, Iran
}

\begin{abstract}
Introduction: The population of older adults is increasing as science progresses and health conditions improve. Social, psychological and behavioral factors will influence life satisfaction in older adults. We aimed to assess multiple factors associated with life satisfaction in older adults in Qom city, Iran.

Material and methods: It was a descriptive-analytical study which has conducted on 679 older adults through convenience sampling from Qom city, Iran during 2018. The data were collected using demographic characteristics, life satisfaction, well-being, cognitive status, social support, and daily activities of life questionnaire. Data were analyzed by SPSS version 22 software and independent $t$-test, ANOVA, Pearson's correlation coefficient and multiple regression analysis.

Results: The mean older adult's age was $70.43 \pm 7.62$ years. The mean life satisfaction score was $13.77 \pm 3.73$. The results showed a significant relationship of job and education with life satisfaction $(p<0.001)$. The results also showed that social support $(p=0.001)$ and daily activities $(p=0.017)$ significantly predict the level of life satisfaction, and the dimensions of health $(p=0.001)$ and cognitive status $(p=0.007)$ have a larger share in predicting the satisfaction of older adults' life.

Conclusions: We found that some parts of life changes in older adults can be predicted with the help of social support, health status, cognitive status, and everyday life activities. Therefore, in order to increase the level of life satisfaction of older adults, it is suggested that promotion of social support, health status, and cognitive status be provided.
\end{abstract}

Key words: life satisfaction, older adults, psychological, sociological factors.

\section{Introduction}

Older adults are a group of people who, in the contemporary world, constitute a growing population with special needs, related to the huge advances in science and technology, especially the promotion of health sciences. Increase of the aging population is a challenge for the world and governments are required to pay more attention to this group [1]. According to the World Health Organization (WHO), currently around 650 million people are over 60 years old and by 2050 this figure is expected to reach two billion. Today, $60 \%$ of the world's older adults live in developing countries, which will reach $80 \%$ by 2050 . The older adult population in Iran is increasing, and its population is expected to increase from $8.2 \%$ in 2011 to $10 \%$ in 2021 [2].

Life satisfaction has recently been introduced as the best indicator of the quality of life. Satisfaction with life is a kind of general and deep inner happiness that emanates from individual experiences in the outside world. In other words, it expresses the positive attitude of the individual towards his life and reflects the indi- vidual's feelings about his past, present or future [3]. Older adults having higher life satisfaction also appear to be at higher levels in promoting health behaviors [4]. However, it is usually difficult to achieve higher levels of life satisfaction with increasing age and physical and psychological problems [5]. Lifestyle of older adults plays an important role in their satisfaction. It seems that economic, social and cultural factors affect life satisfaction of older adults [6]. Many satisfactory predictive factors of older adults are social, psychological, and behavioral, and potentially changeable. Success in older adults is not affected by individual genetic factors, but more factors such as the level of physical activity, social interaction and social support will be effective in older adults' satisfaction [7]. The results of a study by Li et al. showed that life satisfaction in older adults is associated with the level of education, financial resources, self-assessment of health, receiving financial support from the children and satisfying their support, staying at home, seeing and visiting neighbors, and inviting them to dinner [8]. Didino et al. reported that factors such as income, level of home equipment and 
anxiety and loneliness affect life satisfaction of older adults [9]. Bishop et al. described individual access to key and important life sources as factors influencing life satisfaction. These resources include material, social or personal resources that the older adults have to offer, which can be referred to as the main sources for advancing and maintaining the well-being of individuals. These resources can also help older adults achieve their personal goals and meet the basic physical and psychological needs [10]. Considering that life satisfaction is considered as a subjective concept that assesses several dimensions including health, psychological, and social in older people's life, it could be an indispensable part of successful aging [11]. Therefore, the evaluation of social, psychological and health factors could have pivotal role for achieving successful aging. In this study, we intended to assess multiple factors associated with life satisfaction in older adults.

\section{Material and methods}

It was a descriptive-analytical study which has conducted on 679 older adults through convenience sampling from Qom city, Iran during 2018.

The research population consisted of all older adults living in Qom city, and we selected this city because it is one of the metropolises in Iran and they are inhabited by different Iranian ethnic groups. G*Power-3 software was used to calculate the sample size. Considering the 95\% confidence level, 80\% test power, and $r=0.30$, 544 were calculated according to the study of Eshkoor et al. [12]. To compensate for sample loss and incomplete questionnaires, $20 \%$ of the sample size was added to the final samples and the final sample size was calculated as 679 .

Inclusion criteria for the study included speaking ability, consent to participate in the study, age over 60 , and lack of cognitive problems such as Alzheimer's. Older adults' medical records were used to judge these criteria as well as older adults' patient records. The exclusion criterion was dissatisfaction with continued cooperation. Data collection was done in one step using a questionnaire consisting of 6 sections by researchers in public places where the target group was referred. The questionnaires were filled out by well-educated older adults under the guidance of supervisors, and for low-educated or illiterate elders, questionnaires were completed through an organized interview.

\section{Research fools}

Demographic information questionnaire: The questionnaire included age, gender, employment status, marital status, educational level, income source, number of children and housing status.
Life Satisfaction Index-Z (LSI-Z): This questionnaire has 13 questions, designed in 1969 by Wylie, Wood, and Sheafor. Each of the questions is answered in the form of "I do not know", "agree" and "disagree", and the 2-1-0 system is used for scoring the answers.

Thus, "I do not know" is scored zero; in positive questions, "agree" is scored 2 and "disagree" is scored 1 , and in the case of negative questions, "disagree" is scored 2 and "agree" is scored 1. The total score of life satisfaction is estimated in the range 0-26. Obviously, a higher score indicates a higher level of life satisfaction. Regarding the interpretation of the LSI-Z score, $\leq 12$ indicates a low level of satisfaction, 13-21 average satisfaction, and $22 \leq$ high satisfaction [13].

In Iran, the validity and reliability of this questionnaire have been verified in different studies. Taghribi et al. reported the reliability coefficient of the tool through re-test with intraclass correlation coefficient as 0.93. Cronbach's $\alpha$ coefficient of the present questionnaire was estimated as 0.79 [14].

Activities of daily living (ADL): In the present study, the 6-item version of Katz was used. This tool includes personal grooming items, eating, dressing, sitting, bathing, and controlling urine and feces. Each item has three options: "dependent" (zero points), "need help" (1 point) and "independent" ( 2 points).

The overall ADL score is from zero to 12 and each test is ranked "dependent" (0 to 4 points), "need help" ( 5 to 8 points) and "independent" (9 to 12 points) based on the score it earns [15].

WHO (Five) Well-Being Index (1998 version): This scale consists of five questions that assess the mental status of individuals over the past two weeks in a table. These five questions with the Likert technique include 6 options of "at all times" (score 5), "most often" (score 4), "slightly more than half of the times" (score 3), "slightly less than half of the times" (score 2), "sometimes" (score 1) and never (0 score). To compute the points, the numbers in the squares are summed up and multiplied by 4 . The resulting number ranges from zero to 100 , which points to a greater degree of well-being.

Medical Outcomes Survey (MOS): This scale was created in 1991 by Sherborne and Stewart and provides social support received by the subject. The questionnaire, which is a self-report tool, has 19 sentences, and the subject specifies the amount of disagreement or agreement with each of the expressions by a 5-point Likert scale (1 point for "never" to 5 points for "always"). The lowest score in this test is 19 and the highest score is 95. To obtain the overall score, all scores are combined.

A high score of the subject on this scale indicates that the subject has favorable social support. To obtain the score for each sub-scale, it is enough to merge the scores for the phrases associated with each sub-scale. The validity and reliability of this scale have been reported as desirable. The reliability of this test has been 
reported using Cronbach's $\alpha$ coefficient in the range of $0.74-0.93$ [16].

Abbreviated mental test (AMT): This questionnaire contains 10 simple and short questions that measure orientation, focus/attention, short-term memory, and long-term memory, and is used to screen for cognitive impairment including dementia and delirium in the elderly. The short form consists of 10 questions with 10 points, and takes only 3 minutes to complete.

This test has been validated in Iran and its scoring is such that a score below 6 indicates a moderate cognitive disorder, a score of 6 to 8 indicates a mild disorder, and a score higher than 8 means a lack of cognitive disorder. The intrinsic reliability of the Persian version of the AMT is acceptable (Cronbach's $\alpha$ coefficient is 0.76), and its external reliability is also desirable (inter-group correlation coefficient is 0.89) [17].

In order to observe ethical considerations in this study, the participants in the research project were informed about the goals of the study. Information was also collected without the need to include personal details and in an organized manner.

Data analysis was done using SPSS software version 22 at two descriptive and inferential levels. Descriptive statistics of mean and standard deviation and frequency distribution were used at the descriptive level. Independent t-test, ANOVA, Pearson's correlation coefficient and multiple regression analysis were used at the inferential level. The significance level of these tests was considered less than 0.05 .

\section{Results}

The mean age of the older adults was $70.43 \pm 7.62$ years in the range of 60 to 92 years. Also, $68.9 \%$ (468 cases) were female and $31.1 \%$ (211 people) were male. $51.8 \%$ (352) were married, $46.5 \%$ (316) had lost their spouses and only $1.1 \%$ (11) were divorced.

The majority of participants, 91.8\% (623), were illiterate and/or low-educated. Also, the mean life satisfaction score in the case group was $13.77 \pm 3.73$ (range 3-26), of whom $41.8 \%$ (284 people) had low life satisfaction, $54.2 \%$ (368 people) had medium life satisfaction and $4 \%$ (27 people) had high life satisfaction.

According to the independent t-test, life satisfaction was significantly correlated with the employment status and education of the older adults $(p<0.001)$, so that the mean life satisfaction score in the older adults who were employed and had university education was significantly higher. ANOVA test results showed no significant difference in mean life satisfaction score in terms of the number of children $(p=0.059)$ and housing status $(p=0.493)$ (Table 1$)$.

There was a significant positive correlation of life satisfaction scores with health status, cognitive status and social support $(p<0.001, r=0.333, p<0.001$, $r=0.186, p<0.001, r=0.291)$. However, there was no relationship of life satisfaction with age and daily activities of subjects $(p=0.614, r=-0.019, p=0.564$, $r=0.022$ ) (Table 2).

Stepwise linear regression analysis was used to investigate the effect of each of the predictors affecting life satisfaction in the older adults. According to the results, there was a significant positive relationship of health $(\beta=0.253)$, social support $(\beta=0.204)$ and cognitive status ( $\beta=0.17$ ) with life satisfaction, and the relationship between daily activities of life and life satisfaction was negative and significant $(\beta=-0.91)$.

According to the determination coefficient, about $16.3 \%$ of the changes in life satisfaction of older adults were due to the four variables mentioned in the regression model. The regression model had acceptable fitness $(p=0.001, F=23.21)$ (Table 3 ).

\section{Discussion}

The purpose of this study was to evaluate multiple factors associated with life satisfaction in older adults. The results showed that the majority of the older adults studied had low or moderate life satisfaction, which, in general, did not show favorable conditions. A glance at past studies suggests that the satisfaction of older adults' life is not favorable $[8,18]$. However, in some studies, the satisfaction of older adults with their current life is favorable $[9,12]$. Perhaps this is because the standard LSI-Z questionnaire was used in this study, but in other studies, a researcher-made checklist was used. Also, cultural differences may be the reason for differences in the state of satisfaction with the lives of individuals. In terms of demographic variables, life satisfaction was higher in men than in women. In the study of Hosseini et al., there was a significant difference between older men and women in terms of life satisfaction [19]. Furthermore, one survey in an urban region in China indicated that older women were more likely to be satisfied with their life [20], which contradicted our results. A possible explanation for this is that the health condition among older women might be lower than in older men, so it could result in lower life satisfaction [21]. Moreover, this difference can be explained through the lower number of older men in comparison with older women (gender difference); an unintended bias should be taken into consideration [22]. The findings of a study [12] contradicted our result that men have a higher life expectancy than women, which may be due to the amount of social activities and differences in level of education (men had a higher level of education).

In the present study, married older adults reported a higher life satisfaction than divorced ones or older adults who had lost their spouse. In other studies $[23,24]$, married people had a higher life satisfaction than non-spouses. The possible reason was that in 
Table 1. Comparison of life satisfaction at different levels of the variables studied

\begin{tabular}{|c|c|c|c|c|}
\hline \multirow[t]{2}{*}{ Variable } & \multirow[t]{2}{*}{ Variable levels } & \multirow[t]{2}{*}{ Number (\%) } & Life satisfaction & \multirow[t]{2}{*}{$p$-value } \\
\hline & & & Mean \pm SD & \\
\hline \multirow[t]{6}{*}{ Employment status } & Current worker & $18(2.7)$ & $17.61 \pm 2.97$ & $<0.001$ \\
\hline & Employed after retirement & $16(2.4)$ & $13.75 \pm 3.19$ & \\
\hline & Retired & $175(25.8)$ & $14.38 \pm 3.70$ & \\
\hline & Unemployed & $49(7.2)$ & $13.67 \pm 3.55$ & \\
\hline & Housewife & $273(40.2)$ & $14.19 \pm 3.81$ & \\
\hline & Others & $148(21.8)$ & $11.85 \pm 2.93$ & \\
\hline \multirow[t]{5}{*}{ Level of education } & Illiterate & $330(48.6)$ & $12.96 \pm 3.27$ & $<0.001$ \\
\hline & Elementary & $293(43.2)$ & $13.71 \pm 3.76$ & \\
\hline & Secondary & $19(2.8)$ & $18.63 \pm 1.21$ & \\
\hline & High school & $19(2.8)$ & $18.84 \pm 1.46$ & \\
\hline & Academic & $18(2.7)$ & $19.16 \pm 1.50$ & \\
\hline \multirow[t]{4}{*}{ Income } & Shopping and saving & $35(5.2)$ & $14.51 \pm 4.59$ & 0.001 \\
\hline & Buy without saving & $147(21.6)$ & $13.32 \pm 3.35$ & \\
\hline & Just buy the necessary supplies & $431(63.5)$ & $14.09 \pm 3.78$ & \\
\hline & Lack of purchasing power & $431(63.5)$ & $14.09 \pm 3.78$ & \\
\hline \multirow[t]{3}{*}{ Number of children } & 3 or fewer & $175(25.8)$ & $13.96 \pm 3.78$ & 0.059 \\
\hline & $6-4$ & $374(55.1)$ & $13.93 \pm 3.88$ & \\
\hline & 7 or more & $130(19.1)$ & $13.07 \pm 3.10$ & \\
\hline \multirow[t]{2}{*}{ Gender } & Male & $211(31.1)$ & $14.33 \pm 3.73$ & 0.009 \\
\hline & Female & $468(68.9)$ & $13.52 \pm 3.71$ & \\
\hline \multirow[t]{3}{*}{ Marital status } & Married & $352(51.8)$ & $14.27 \pm 3.87$ & 0.013 \\
\hline & Widow/widower & $316(46.5)$ & $13.32 \pm 3.52$ & \\
\hline & Divorced & $11(1.6)$ & $14.16 \pm 3.55$ & \\
\hline \multirow[t]{3}{*}{ Housing situation } & Personal & $620(91.3)$ & $13.74 \pm 3.67$ & 0.493 \\
\hline & Leased & $35(5.2)$ & $13.77 \pm 4.33$ & \\
\hline & Accommodation without payment & $24(3.5)$ & $14.66 \pm 4.28$ & \\
\hline
\end{tabular}

Table 2. Correlation between life satisfaction and the study variables

\begin{tabular}{lcccccc}
\hline Variable & & Age & Wellness status & Cognitive status & Social support & Daily activities \\
\hline Life satisfaction & $r$ & -0.019 & 0.333 & 0.186 & 0.291 & 0.022 \\
\cline { 2 - 7 } & $p$ & 0.614 & $<0.001$ & $<0.001$ & $<0.001$ & 0.564 \\
\hline
\end{tabular}

Table 3. Results of regression analysis of factors affecting life satisfaction

\begin{tabular}{|c|c|c|c|c|c|}
\hline Predictive variable & B & S.E. & $\beta$ & $t$ & $p$-value \\
\hline Constant & 8.062 & 0.817 & - & 9.761 & 0.001 \\
\hline Wellness & 0.142 & 0.231 & 0.253 & 6.103 & 0.001 \\
\hline Social support & 0.048 & 0.009 & 0.204 & 5.362 & 0.001 \\
\hline Cognitive status & 0.177 & 0.065 & 0.107 & 2.719 & 0.007 \\
\hline Everyday life activities & -0.109 & 0.045 & -0.091 & -2.392 & 0.017 \\
\hline \multicolumn{6}{|c|}{$r=0.403, r^{2}=0.163, F=23.21, p<0.001$} \\
\hline
\end{tabular}

married people the benefit of joint activities and emotional support may lead to self-esteem and psychological well-being, due to which life satisfaction will be increased.

In addition, in the present study, life satisfaction was associated with the employment status of older adults; those who were employed had higher satisfaction than other occupational groups. This finding was in contrast with some studies [12, 24, 25]. The difference between the findings could be due to dissimilarity of research samples in terms of economic, social and cultural conditions, which can affect life satisfaction in the elderly. 
In this study, life satisfaction was associated with educational level of the subjects, so that life satisfaction in people with academic education was significantly higher than that in other groups. The findings of some studies $(8,24)$ were consistent with the present study. However, the results of the study by Eshkoor et al. [12] contradicted this finding. Perhaps the reason for the inconsistency is the use of the standard LSI-Z questionnaire in this study and the use of a researcher-made checklist in other studies.

In the present study, there was a significant relationship between life satisfaction and the source of income, so that the mean score of life satisfaction in people who had the ability to buy and save was higher than that in other people. Didino et al. [9] also reported that higher income levels for older adults were associated with higher living standards. In one study [26], life satisfaction was also associated with the economic situation of the older adults. The results of another study [12] contradicted the findings of the present study. Cultural differences can be the cause of the difference in the state of satisfaction with the lives of individuals. In this study, life satisfaction was higher in elderly persons with fewer children, but this difference was not significant. Also, there was no relationship between life satisfaction and housing status in the present study. Findings of the research by Eshkoor et al. [12] were consistent with the present study. However, in the study of Lim and colleagues, life satisfaction was associated with housing status [27]. In the study of Li et al., life satisfaction was associated with their children's homes. In the study of Karimi et al. [28], the mean score of life satisfaction in the group of older adults living in the home was significantly higher than that in other groups.

In the present study, there was no relationship between life satisfactions and age. The study of Eshkoor et al. [12] also reported the lack of effect of the age factor on life satisfaction. However, Angelini et al. [29] stated that with increasing age, the level of life satisfaction increased.

In the present study, a direct and significant correlation was found between life satisfaction and health status. The results of some studies [30, 31] were consistent with this finding. The results of this study showed a direct correlation between life satisfaction and cognitive status. In the study of Eshkoor et al. [12], unlike the present study, there was no relationship between cognitive status and life satisfaction. With the decline of cognitive functions over time, older people are increasingly reluctant to perform routine personal activities and become more dependent on others, and in advanced stages of the disorder, they need to be admitted to hospitals and clinics. These conditions reduce self-esteem, anxiety, and depression in them, which affects the quality of life in terms of life satisfaction [32].
According to the results of this study, a direct and significant correlation was found between social life satisfaction and social support. Li et al. [8] confirmed this finding in their study. Seeman and Adler [7] considered interactions and social support effective for the satisfaction of older adults. Young found in their research that family support increased life satisfaction in older adults [33]. In Iran, Babapour et al. [34] also reported a significant relationship between social support and life satisfaction in the elderly. Given that Iran's society is aging and older people are being transferred to institutions more than ever, it can be anticipated that more elderly people will be at risk of falling social support, and maybe their life satisfaction may be reduced. In this research, there was also no relation between daily activities of life and life satisfaction. However, in the study of Good et al., unlike the present study, there was a significant relationship of life satisfaction with daily activities of life and the state of independence [35]. In the present study, health, social support, daily activities of life and cognitive status were identified as life-satisfaction predictors, so that health, social support and cognitive status had a positive relationship with life satisfaction, but there was a significant negative relationship between life satisfaction and the daily activities of life of the people under study. Perhaps the reason for this is the cultural differences between Iranian societies and other societies. In Iranian societies, being dependent on everyday activities as well as social support by others, especially children, and also without critical disease especial in older women such as cervical-vaginal infections will be increased life satisfaction in this age group $[36,37]$. Based on the results, it can be argued that by focusing on some of the psychological and social factors mentioned above, the elderly's satisfaction with their lives can be affected. Therefore, it is recommended to plan families in order to determine the causes of life satisfaction reduction with regard to its predictors.

\section{Limitations of study}

Limitations were the low literacy level of the majority of older adults under study, length of questions in the questionnaire, and the elderly's boredom in responding to them, which prolonged the work and reduced the quality of the answers, and there is a widespread negative attitude that many studies on older adults are not aimed at helping them, but for researchers to advance their own goals. Another limitation of the present study was the cross-sectional nature of the study, which made it difficult to determine the causal relationship. Hence, it is advisable to use longer and more comprehensive studies of factors affecting life satisfaction and causal relationships. On the other hand, performing this study 
with a case-control design could provide valuable information to the research team.

\section{Conclusions}

Our findings have shown that life satisfaction was not favorable in older adults. Therefore, the necessity of using solutions to improve life satisfaction in the older adult community is felt in this category. Social support, health and cognitive status and daily activities of life as well as life satisfaction determinants were reported. Our research has demonstrated that older adults with fewer children had a higher score in life satisfaction, which was contrary to older people's traditional attitudes towards having more children in the family. Unlike other research carried out in this area, we did not find a significant association between being female and high life satisfaction. Thus, broader research is also needed to determine this discrepancy among older women who live in religious cities such as Mashhad and Qom. Considering that the mentioned factors explained $16.3 \%$ of life satisfaction, other studies are needed to identify other factors affecting life satisfaction.

\section{Acknowledgements}

This study was approved by the Ethics Committee of Ahvaz Jundishapur University of Medical Sciences, Ahvaz with reference number: IR.AJUMS.1397.898 and all subjects provided signed consent and support by the deputy of research at Ahwaz Jundishapur University of Medical Sciences.

All authors of the manuscript have read and agreed to its content and are accountable for all aspects of the accuracy and integrity of the manuscript in accordance with ICMJE criteria.

The article is original, has not already been published in a journal, and is not currently under consideration by another journal.

The authors are grateful to the Department of Public Health and Social Determinants of Health Research Center in Ahvaz Jundishapur University of Medical Sciences. The authors also express gratitude and appreciation for the cooperation of the older adults in this research.

\section{Disclosure}

The authors report no conflict of interest.

\section{References}

1. Sourour Y, Houda BA, Maroua T, et al. Hospital morbidity among elderly in the region of Sfax, Tunisia: epidemiological profile and chronological trends between 2003 and 2015. Clin Epidemiol Glob Health 2019; 7: 131-135.
2. Statistical Center of Iran. Implementation of the 2011 Iranian Population and Housing Census 2011. Available from: http://www.who.int/ kobe_centre/ageing/en/-2011.

3. Yeniaras V, Akarsu TN. Religiosity and life satisfaction: a multi-dimensional approach. J Happiness Stud 2017; 18: 1815-1840.

4. Vijayakumar G, Devi ES, Jawahar P. Life satisfaction of elderly in families and old age homes: a comparative study. Int J Nurs Educ 2016; 8: 94-99.

5. Papi S, Karimi Z, Zilaee M, Shahry P. Malnutrition and its relation to general health and multimorbidity in the older people. J Holistic Nur Midwifery 2019; 29: 228-235.

6. Gholizadeh A, Shirani E. Relationships among individual, familial, social, economic and life satisfaction of the elderly of Isfahan. Appl Sociol 2010; 21: 69-82.

7. Seeman TE, Adler N. Older Americans: who will they be? Natl Forum 1998; 78: 22-26.

8. Li H, Chi I, Xu L. Life satisfaction of older Chinese adults living in rural communities. J Cross Cultural Gerontol 2013; 28: 153-165.

9. Didino D, Frolova EA, Taran EA, Gorodetski K. Predictors of life satisfaction among older adults in Siberia. Future Academy, Tomsk 2016, 400407.

10. Bishop A, Martin P, Poon L. Happiness and congruence in older adulthood: a structural model of life satisfaction. Aging Mental Health 2006; 10: 445-453.

11. Fertelli TK.,Deliktas T. A study on the relationship between perceptions of successful aging and life satisfaction of Turkish elderly people. Perspect Psychiatr Care 2020; 56: 386-392.

12. Eshkoor SA, Hamid TA, Mun CY, Shahar S. An investigation on predictors of life satisfaction among the elderly. Int J Adv Social Sci 2015; 1: 207-212.

13. Wood V, Wylie ML, Sheafor B. An analysis of a short self-report measure of life satisfaction: correlation with rater judgments. J Gerontol 1969; 24: 465-469.

14. Tagharrobi Z, Tagharrobi L, SharifiKh, Sooki Z. Psychometric evaluation of the Life Satisfaction Index-Z (LSI-Z) in an Iranian elderly sample. Payesh 2011; 10: 5-13.

15. Katz S, Ford AB, Moskowitz RW, Jackson BA, Jaffe MW. Studies of illness in the aged: the index of ADL: a standardized measure of biological and psychosocial function. Jama 1963; 185: 914-919.

16. Sherbourne CD, Stewart AL. The MOS social support survey. Soc Sci Med 1991; 32: 705-714

17. Bakhtiyari F, Foroughan $\mathrm{M}$, Fakhrzadeh $\mathrm{H}$, et al. Validation of the persian version of abbreviated mental test (AMT) in elderly residents of Kahrizak charity foundation. Iran J Diab Metabol 2014; 13: 487-494.

18. Borhaninejad V, Nabvi S, Lotfalinezhad E, Amini F, Mansouri T. Relationship between Social participation and lifesatisfaction among older people. J N Khorasan Uni Med Sci 2017; 8: 701-711.

19. Hosseini SM, Rezaee AM, Keykhosravi Z. A Comparison of old men and women's social support, life satisfaction, happiness and depression. J Woman Soc 2012; 4: 143-161.

20. Lu N, Spencer M, Sun Q, Lou VW. Family social capital and life satisfaction among older adults living alone in urban China: the moderating role of functional health. Aging Ment Health 2021; 25: 695-702.

21. Kim IH. Age and gender differences in the relation of chronic diseases to activity of daily living (ADL) disability for elderly South Koreans: based on representative data. J Prev Med Public Health 2011; 44: 32-40.

22. Holdcroft A. Gender bias in research: how does it affect evidence based medicine? In: SAGE Publications. Sage UK, London 2007.

23. Botha F, Booysen F. The relationship between marital status and life satisfaction among South African adults. Acta Academica 2013; 45: 150-178.

24. Cha YJ. Correlation between Leisure activity time and life satisfaction: based on KOSTAT time use survey data. Occup Ther Int 2018; 2018: 5154819 .

25. Alden L, Hammarstedt M. Self-emplioyment and life satisfaction among the elderly. Survey-based evidence from Sweden. Linnaeus Univ Discrimin Integra 2017; 5: 1-32.

26. Lim HJ, Min DK, Thorpe L, Lee CH. Multidimensional construct of life satisfaction in older adults in Korea: a six-year follow-up study. BMC Geriatr 2016; 16: 197.

27. Jahangiri Zadeh P, Khodabakhshi Koolaee A. The relationship between self-concept, life satisfaction and hope among retired and housewife older adults' women. J Gerontol 2016; 1: 19-28. 
28. Karimi T, Nouhi E, Iranmanesh S. Comparing Life satisfaction of elderly between nursing home residents and seniors living in their own homes in Isfahan. Elderly Nur J 2018; 1: 43-54.

29. Angelini V, Cavapozzi D, Corazzini L, Paccagnella O. Age, health and life satisfaction among older Europeans. Soc Indic Res 2012; 105: 293-308.

30. Jafari E, Najafi M, Sohrabi F, Dehshiri GR, Soleymani E, Heshmati R. Life satisfaction, spirituality well-being and hope in cancer patients. Procedia Soc Behav Sci 2010; 5: 1362-1366.

31. Gongora VC, Castro Solano A. Well-being and life satisfaction in Argentinean adolescents. J Youth Stud 2014; 17: 1277-12791.

32. Clare L, Woods RT. Cognitive training and cognitive rehabilitation for people with early-stage Alzheimer's disease: a review. Neuropsychol Rehab 2004; 14: 385-401.

33. Yunong $\mathrm{H}$. Family relations and life satisfaction of older people: a comparative study between two different hukous in China. Ageing Soc 2012; 32: $19-40$.

34. Babapour M, Raheb G, Eglima M. The relationship between social support and life satisfaction among elderly nursing home residents in Tehran. Iranian J Ageing 2014; 9: 6-13.

35. Good GA, La Grow SJ, Alpass FM. A study of older adults: observation of ranges of life satisfaction and functioning. N Z J Psychol 2011; 40 96-103.

36. Cheraghi M, Rahimi Z, Parsa S. Prevalence of cervical-vaginal infections in the pap-smear samples in Iran. Glob J Health Sci 2014; 6: 201-206.

37. Papi S, Ramezani T, Aalipour R, Naderiyan S, Fadayevatan R, Nazarpour A. Assessment of physical activity status and its effective factors in elderly people of Khorramabad City. Health Dev J 2020; 8: 280-291. 